\title{
LA RIBERA MEXICANA DEL RÍO SUCHIATE, TERRITORIO FRONTERIZO EN EXTINCIÓN
}

\author{
Conflictos generados por la abundancia del recurso hídrico
}

\author{
Jonathan Gómora Alarcón \\ atlasgeografico@gmail.com
}

CIESAS-Sureste

\section{RESUMEN}

En la frontera entre México, Guatemala y Belice hay más de seis ríos que atraviesan el límite del territorio del país guatemalteco y se vierten en el mexicano y en el beliceño. Pero sólo tres son los conocidos propiamente como ríos fronterizos. Dos pertenecen a la división de México y Guatemala: el Suchiate y el Usumacinta, y el tercero, Río Hondo, corre entre México y Belice. La desaparición paulatina de la ribera suchiatense, erosionada por los fenómenos meteorológicos, entre otros eventos, ha sido motivo de preocupación local, mas no internacional. Con base en el trabajo de campo realizado en la parte baja de la cuenca transfronteriza de dicha ribera, se presenta la situación actual de los ejidos y los problemas con que se enfrentan por los trabajos hidráulicos realizados para la contención y el encauzamiento del río, que no toman en cuenta la participación social de los actores locales.

Palabras claves: conflicto, agua, frontera sur, río Suchiate.

\section{THE MEXICAN RIVERBANK OF THE SUCHIATE RIVER, A FRONTIER TERRITORY ENDANGERED}

\section{Conflicts caused by water resource plentiful}

\section{ABSTRACT}

Along the border between Mexico, Guatemala and Belize there are more than six rivers that cross the Guatemalan border and flow into Mexico and Belize. However, only three are known as border rivers. Two pertain to the border between Mexico and Guatemala: the Suchiate and the Usumacinta. The third one, the Hondo River, flows between Mexico and Belize. Eroded by weather events, among events of other kinds, the gradual disappearance of the riviera to the Suchiate River has given rise to deep concern. This concern, however, is more local than international. Fieldwork conducted in the lower transborder water basin of the Suchiate Riviera identified the current situation of the communal lands (known as ejidos in Mexico) and the problems faced as a result of the hydraulic works. These works, carried out to contain and engineer the river, fail to take into account the social participation of local stakeholders.

Key words: conflict, water, southern border, Suchiate River. 


\section{INTRODUCCIÓN}

El agua es uno de los recursos más importantes de la vida en nuestro planeta. El ser humano lo ha sabido explotar en todas sus variantes: lo ha utilizado para el consumo, la navegación, la industria y, debido a su carácter estratégico, ha sido motivo de disputas, además de considerarse divisor de territorios. Su presencia ha sido vital para la supervivencia humana, y no se ha podido remplazar. Calcular su cantidad es un asunto complicado debido a que su naturaleza es dinámica en el tiempo y en el espacio (Ávila 2009: 3). Ignora fronteras políticas y suscita usos múltiples y concurridos. El crecimiento poblacional y los patrones de consumo han contribuido al incremento de las tensiones sobre este recurso en el mundo actual (Gérardot et al. 2011:83).

La crisis del agua, según Santacruz (2010:1), se vincula con la disminución de la disponibilidad hídrica y con los problemas ambientales asociados con su uso; asimismo, se relaciona con la reducción de la disponibilidad de líquido potable, en calidad y en cantidad adecuadas. Es por esto que los conflictos $^{1}$ por el agua se han desarrollado en diversas escalas espaciales y niveles entre los individuos que usan este recurso en cualquier territorio.

El agua en las fronteras, ya sea en forma de ríos, lagos o mares, se ha convertido en uno de los temas más importantes en materia de seguridad nacional y objeto de estudio de la hidropolítica desde finales del siglo $\mathrm{XX}$, debido a que estos cuerpos de agua atraviesan la frontera o la construyen como lindero entre dos o varios Estados-nación. A pesar de esto, los ríos siguen en constante crisis por las causas antes men-

${ }^{1}$ Olvera et al. (2011) mencionan la concepción básica de un conflicto: dinámicas negativas, agresiones, confrontaciones, tensiones, interacciones y, en cierto momento, hostilidades armadas en Estados. Se establece entonces un rango del conflicto que abarca aspectos políticos, sociales, económicos y que puede llegar hasta los combates militares; sin embargo, estos no necesariamente son violentos. Precisan a la vez que las disputas se generan por los diferentes puntos de vista sobre la forma en que se usan los recursos, en este caso, el agua. También abarcan la forma como se desarrollan diferentes intereses y qué tipo de políticas les rigen, por lo que entran en conflicto el acceso, el control, el uso y la gestión del recurso hídrico (Olvera et al. 2011:109-110). cionadas. En suma, se tienen dos variables a considerar: el río como recurso y el río como frontera.

Los ríos frontera se localizan en cuencas transfronterizas. ${ }^{2}$ Estas conforman una región donde se unen dos o más Estados, es decir, una cuenca de esa índole no respeta las fronteras, sino todo lo contrario, las atraviesa y une porciones territoriales de los Estados. El tema del agua fronteriza, por lo tanto, representa uno de los más relevantes en materia de política internacional, puesto que abarca cuestiones tanto de diplomacia como de respeto del caudal de los cuerpos de agua, los cuales sirven como límite entre las diferentes poblaciones que habitan sus respectivas riberas.

Tal es el caso de las localidades ubicadas en las partes bajas de las cuencas transfronterizas, donde las relaciones internacionales de países vecinos se ven amenazadas por enfrentamientos, disputas, choques o desacuerdos entre poblaciones que buscan el aprovechamiento de un recurso tan limitado como el agua o la obtención de una mayor extensión territorial para el desarrollo de actividades económicas, por lo cual se apropian de las riberas.

Por otro lado, Wolf et al. (2005:157) señalan que «Las disputas por el agua son atribuidas y/o relacionadas con tres aspectos principales: cantidad, calidad y disponibilidad». En cualquiera de estos casos pueden derivar en disputas abiertas o en conflictos armados. De manera general, «Las tensiones potenciales para el agua aumentan cuando el recurso no es distribuido a la población» (Olvera et al. 2011:10). Por lo tanto, cuando la presión sobre el recurso es escasa, los conflictos aparecen entre diferentes usos y usuarios. La segunda causa de conflictos es «La gestión por el agua, cuando esta se centra en la construcción de numerosos equipamientos: bordos, represas, canales, plantas potabilizadoras o de purificación» (Gérardot et al. 2011:83).

Ahora bien, en el contexto de disputas generalizadas por la infraestructura y de crecientes luchas ambientales, estas habilitaciones hidráulicas son cada vez más conflictivas. Los problemas ligados a los desarrollos hidráulicos están estrechamente conectados con los conflictos del uso del agua. En efecto, «La apuesta al servicio de un equipamien-

\footnotetext{
${ }^{2}$ Estructura geomorfológica en la que los caudales de los ríos rebasan el límite político nacional de un Estado. Esto se refiere a que cuando un río desborde el límite geográfico de un país, será denominado transfronterizo (Olvera et al. 2011).
} 
to hidráulico conduce con frecuencia a modificar la disponibilidad del agua en el tiempo y en el espacio, afectando así a los otros usuarios, y exacerba la competencia entre ellos» (Gérardot et al. 2011:83).

Los conflictos por el agua en la frontera sur, en especial en Chiapas, cuentan actualmente con más estudios en México, no así en Guatemala. Y tal vez la razón por la cual no se mira por completo la frontera hídrica es la literatura centrada en la relación Chiapas-Guatemala, en donde existen diversos actores que participan en la cuestión del agua entre ambos territorios. Estos comparten el recurso de los principales ríos, zonas de bosque explotable y una desarrollada actividad poblacional en la frontera (Kauffer 2010c), y, sin embargo, no se toca el tema del agua transfronteriza.

En la cuenca transfronteriza del río Suchiate los conflictos no se relacionan con la escasez del agua. En primer lugar, el aumento en la demanda y la competencia en materia de recursos hídricos en la frontera sur de México no representa un problema. Como señala Kauffer (2012a), ocurre exactamente lo contrario. Existe una gran cantidad de agua, mal repartida, mal utilizada, con problemas resultantes de la aplicación de políticas públicas basadas en respuestas ingenieriles para atacar la erosión de la ribera y rencauzar el río Suchiate.

Debido a tales factores este trabajo señala cuáles son algunos conflictos que se han originado con la movilidad del río y, por ende, de la frontera, en la parte baja de la cuenca transfronteriza del Suchiate. En esta región las relaciones sociales se han visto impactadas por una gran cantidad de problemas debidos a los eventos hidrometeorológicos ocurridos en los últimos años, donde la frontera simplemente se movió, y los gobiernos, tanto mexicano como guatemalteco, no han tomado medidas para evitarlo, y de hecho han llegado a negar que exista ese desplazamiento.

En esta exposición se utilizan los resultados del trabajo de campo realizado en la parte baja de la cuenca, principalmente en tres ejidos: Ignacio López Rayón, La Libertad y Miguel Alemán. En entrevistas a los comisariados y a una representante vecinal, así como a algunos pobladores de los ejidos, se intentó comprobar la hipótesis sobre el desinterés que existe entre los gobiernos de México y Guatemala en hablar de la frontera formada por el río Suchiate, así como la incipiente participación de instituciones como la Comisión Nacional del Agua (Conagua) y la Comisión Internacional de Límites y Aguas (CILA) México, que han desplegado una serie de respuestas de corte ingenieril hidráulico para atacar un problema social, el cual no se ha podido resolver y ya se gesta un descontento entre los pobladores de los ejidos.

Asimismo, se pretende señalar que la crisis del agua mencionada por Santacruz (2010), o los conflictos asociados a trabajos hidráulicos, como informan Wolf et al. (2005) y Gérardot et al. (2011), se complejizan cuando el recurso limitado del agua se encuentra en la frontera y, como ocurre con el Suchiate, forma los límites territoriales entre dos países. Del mismo modo, se describe cómo los habitantes han desarrollado acciones para confrontar las consecuencias del desinterés institucional y de sus obras hidráulicas deficientes.

Hablar del río Suchiate como frontera es, entonces, un imperativo para comprender la construcción de este espacio a partir de la concepción de un cuerpo de agua como una frontera «natural» en un contexto internacional, enmarcado por conflictos en la población de la parte baja de este río, que van desde inundación de terrenos dedicados a la agricultura hasta el cambio de país y, por lo tanto, la pérdida-ganancia de territorio para las poblaciones locales y los propios Estados-nación, de Guatemala y de México.

\section{EJERCICIO DELIMITADOR SOBRE EL SUCHIATE}

La delimitación entre México y Guatemala se realizó durante el siglo XIX, teniendo como marco histórico la independencia de ambas naciones, la de México en 1821 y la de Guatemala en 1822, tanto de la anexión guatemalteca al imperio de Iturbide como de su separación (Camp 1975, Vázquez 2009, Sepúlveda 1958, De la Torre y Cabrera 2008). Esta etapa de intervenciones en México, conflictos y reclamos por Chiapas y el Soconusco, anexiones y pérdidas de territorios, trastornó la relación con Guatemala entre 1824 y 1882 (Pérez 1988, González s. f., Álvarez 2011, De la Torre y Cabrera 2008, Sepúlveda 1958).

Ante la imposibilidad de lograr el objetivo de repatriar Chiapas y el Soconusco, previo a la firma del Tratado de Límites en 1882, la relación binacional entre ambos países se tornó áspera y llena de tensiones que siguen aumentando. Esto pese al discurso de 
hermandad pronunciado por el expresidente Ernesto Zedillo en 2006 durante una reunión con el expresidente de Guatemala, Álvaro Arzú, donde denominó la frontera entre México y Guatemala como una frontera ejemplar (La Jornada 1996).

La actual frontera sur de México abarca $1139 \mathrm{~km}$, de los cuales $962 \mathrm{~km}$ corresponden a Guatemala y $176 \mathrm{~km}$ a Belice. Es menor a la del norte con los Estados Unidos de América, que es de $3153 \mathrm{~km}$ (INEGI s. f.). En este recorrido se encuentran seis cuencas transfronterizas. México y Guatemala comparten en el estado de Chiapas: la del río Suchiate, la del río Coatán, la cuenca del río Grijalva en Chiapas y Tabasco, y la del río Candelaria en Campeche; y las cuencas trinacionales corresponden al río Hondo, compartida por Belice, Guatemala y México (Campeche, Quintana Roo y Yucatán), y la del río Usumacinta, entre Belice, Guatemala y México (Chiapas, Tabasco y Campeche), como se muestra en la figura 1(Kauffer 2012a).

La cuenca transfronteriza del río Suchiate está dividida entre los países de México y Guatemala. Se localiza en el suroriente del territorio mexicano y al suroccidente del guatemalteco, como se puede observar en la figura 2. El Suchiate nace en las faldas del volcán Tacaná en Guatemala y sigue su curso hasta el Océano Pacífico formando la frontera entre ambas naciones, como lo dicta el Tratado de 1882; sin embargo, la mayor parte de la cuenca se localiza en Guatemala, conformándose por diversas microcuencas que drenan agua hasta el cauce principal, como el río Cabuz.

La cuenca se distribuye en una reducida porción del extremo sureste del estado de Chiapas y en el departamento de San Marcos en Guatemala. Recorre los municipios de Suchiate, Frontera Hidalgo, Metapa de Domínguez, Tuxtla Chico, Cacahoatán y Unión Juárez en México (figura 2) y lo municipios de Ocos, Ayutla, Catarina, El Rodeo, El Tumbador, Esquipulas, Palo Gordo, Ixchiguán, La Reforma, Malacatán, Nuevo Progreso, San Marcos, San Pablo, San Rafael Pie de la Cuesta, Sibinal, Tacaná y Tajumulco en Guatemala.

Cuenta con una extensión de $1230 \mathrm{~km}^{2}$, de los cuales $83 \%$ se encuentra en el territorio de Guatemala (Kauffer 2010b). Sin embargo, el informe final de la UNAM (2006), con respecto a la rectificación del Suchiate y la rehabilitación del bordo en Ciudad Hidalgo, refiere una extensión de $1227 \mathrm{~km}^{2}$; por otro lado, Santacruz (2011) señala $1287 \mathrm{~km}^{2}$, lo cual muestra que por más estudios que se hagan se partirá de diferentes puntos de vista para entender, en este caso, cuál es la verdadera extensión de la cuenca, lo cual representa uno de tantos conflictos para abordar el tema. Como señala Kauffer (2012a): «Si los Estados se pusieran de acuerdo, no habría bronca».

Esto trae como primera consecuencia que la información sobre el río y la cuenca sea heterogénea y que no haya desde el inicio, en algo tan básico, una delimitación en común entre ambos países. A pesar de ser la menor en extensión, es la cuenca que posee un número mayor de habitantes, con un total de 274347. Kauffer (2012b) afirma que en la parte mexicana hay una mayor densidad de población con $237 \mathrm{hab} / \mathrm{km}^{2}$ en comparación con la guatemalteca con $220 \mathrm{hab} / \mathrm{km}^{2}$.

En el trabajo de campo realizado en ambos países, del cual el recorrido más extenso fue el del lado mexicano en la parte baja de la cuenca, se pudo observar que en México, en el municipio de Suchiate, según el ingeniero Guillermo Ávila (entrevista 2012) comisariado ejidal de la localidad La Libertad, existe un número aproximado de 8000 habitantes; el comisariado del ejido Ignacio López Rayón, ingeniero Marcelino Valenzuela (entrevista 2012), calculó contar ahí con alrededor de 5000 habitantes; y la encargada de seguridad del ejido Miguel Alemán, Sandra Vilchis (entrevista 2012), dijo que había ahí alrededor de 800 habitantes.

Del lado guatemalteco, Tecún Umán, símil con Ciudad Hidalgo (México), es la cabecera del municipio de Ayutla y ha registrado un crecimiento mayor en su número de habitantes, esto debido a que se ha convertido en la ciudad frontera de Centroamérica en recientes fechas. A pesar de que se ha tratado de detener el paso de salvadoreños, hondureños, nicaragüenses y hasta ecuatorianos, los que lograron llegar hasta esa ciudad se han asentado y por ello aumentó la densidad demográfica.

Sin embargo, el último censo registrado en Guatemala fue el de 2002, por el Instituto Nacional de Estadística (INE), ${ }^{3}$ y a la fecha existe un sistema de aproximaciones hechas para que las autoridades puedan calcular, mediante su tasa de crecimiento anual $(1.8 \%)$, cuánto ha aumentado la población año con

\footnotetext{
${ }^{3}$ La información proviene de las estimaciones realizadas por el gobierno guatemalteco, las cuales proporcionan como fuente al Instituto Nacional de Estadística.
} 
año. Actualmente, en los municipios de la parte baja de la cuenca del río Suchiate en Guatemala, según este sistema, la población es de 38057 personas en Ayutla y de 43231 en Ocós (INE Guatemala 2008).

Esta situación es predominante a nivel nacional en Guatemala pues, de igual modo, en la parte alta de la cuenca suchiatense poblaciones como San Marcos, la cabecera departamental, o Tajumulco, las autoridades no tienen un número exacto y actualizado de la población, además de que las carecen de un conteo propio para saber cuántos habitantes hay por comunidad. Lo que trae como consecuencia un desconocimiento total de las poblaciones que han sido afectadas o que podrán serlo por desastres asociados a fenómenos meteorológicos. Asimismo, con estas aproximaciones estadísticas lo que se cree es que la población crece sin variaciones, es decir, en forma lineal, pero existen factores como la migración que rompen con este sistema de aproximaciones poblacionales.

En la parte baja de la cuenca del río Suchiate, en México, se localiza el municipio de Suchiate, el cual colinda al norte con el de Frontera Hidalgo, al este con Tapachula, al oeste con el país de Guatemala y al sur con el Océano Pacífico, como se puede apreciar en la figura 3. Se extiende territorialmente sobre $236.79 \mathrm{~km}^{2}$ de los $73288.83 \mathrm{~km}^{2}$ que tiene en general el estado de Chiapas, por lo que es un municipio muy reducido en tamaño en comparación con sus vecinos. Su localización lo posiciona en una de las regiones más alejadas del centralismo del país (INEGI 2005).

Figura 1. Mapa de la frontera entre México, Guatemala y Belice, y las cuencas compartidas.

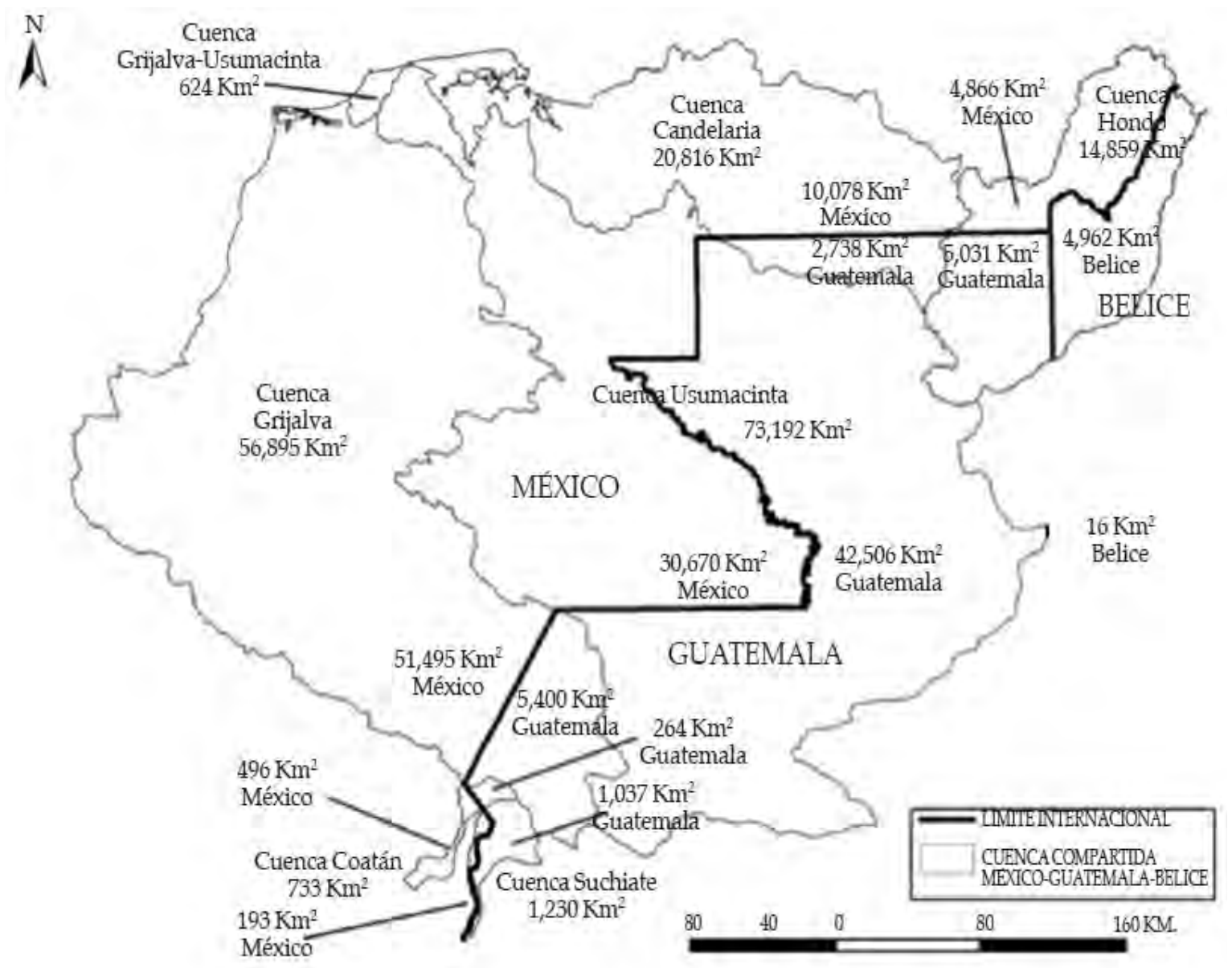

Fuente: Kauffer 2010b: 43, elaborado por Antonino García y Emmanuel Valencia (2010). 
Figura 2. Cuenca del río Suchiate: modelo de elevación digital, hidrografía y municipios.

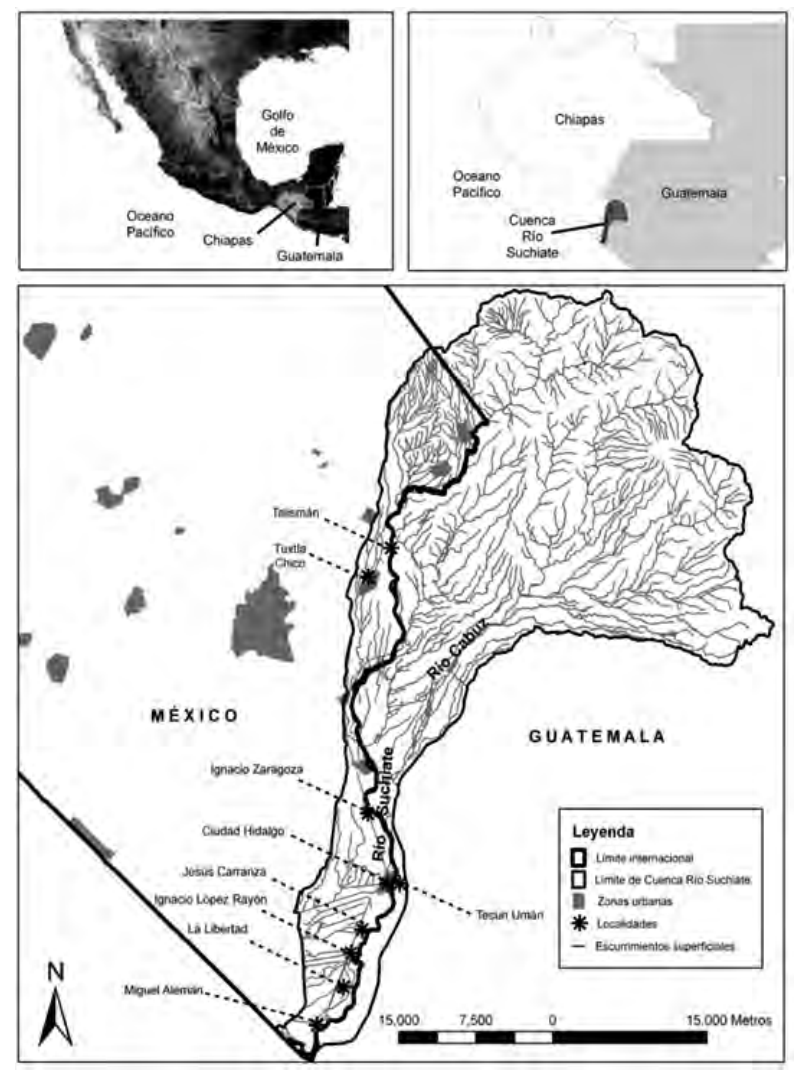

Fuente: elaborado por Emmanuel Valencia Berrera y Edith Kauffer a partir del mapa de cuencas transfronterizas de Antonino García, 2010 (Kauffer, 2010a).

Figura 3. Extensión del municipio Suchiate. Adaptación propia.

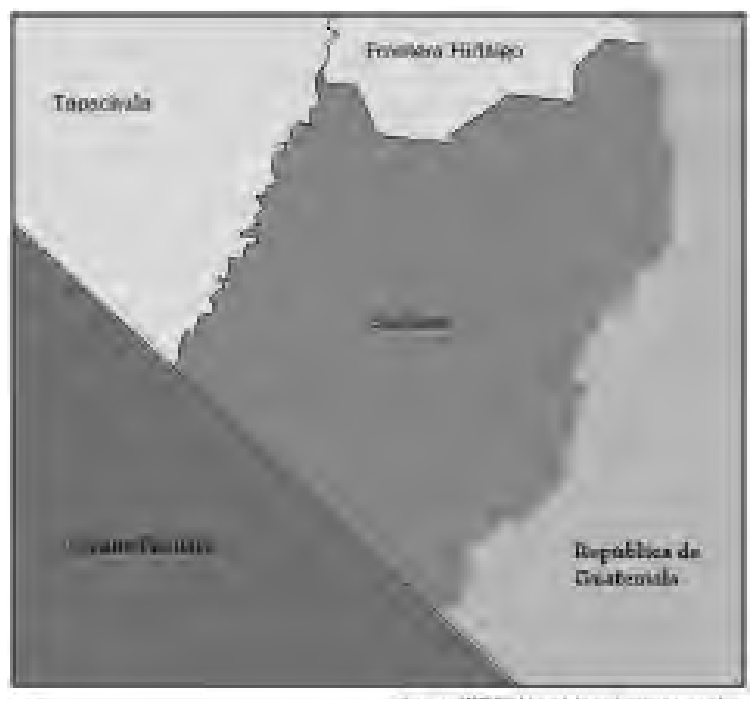

Chiapas: 73288.83. Suchiate: 236.79

Fuente: INEGI, Uso del suelo y vegetación. Periodo de observación de 2002 a 2005.

J. Gómora • La ribera mexicana del río Suchiate, territorio fronterizo en extinción.

Conflictos generados por la abundancia del recurso hídrico 
Esta característica le da una posición estratégica valiosa, pues es un municipio colindante con Guatemala, con puentes internacionales y una frontera que en temporada de estiaje se puede cruzar caminando. Las localidades La Libertad, Ignacio López Rayón y Miguel Alemán, en conjunto, forman un amplio espacio de conflictos en la parte baja de la cuenca de río Suchiate y en su extensión; tienen problemas no solo por la movilidad del río, sino por la pérdida de algunos de sus ejidos, que han quedado en la ribera de Guatemala y porque son localidades asentadas en la ribera del Suchiate, distancia que no supera los 500 metros y en varios casos solo es un muro el que divide al río del ejido o de una vivienda particular.

En la parte baja de la cuenca del Suchiate se han presentado, en los últimos 20 años, severas inundaciones como consecuencia de fenómenos hidrometeorológicos, como el huracán Mitch (1998) y el Stan (2005), una de cuyas repercusiones más importantes y de carácter internacional fue la movilidad de la frontera. Esta frontera fluvial, definida hace más de 150 años, en la actualidad sigue utilizando como criterio de delimitación el thalweg, ${ }^{4}$ a pesar de los conflictos que se han suscitado.

Por esta y otras razones los cuerpos de agua internacionales, mediante el uso del término hidropolítica-que es, en breves palabras, «La manifestación de las tensiones que surgen por el control y el manejo de un recurso cada vez más escaso y estratégico además del análisis de las acciones de cooperación en la materia» (Kauffer 2010b: 195)-, se han convertido en el centro de atención de académicos que se han encargado de analizar las repercusiones políticas dominantes en las cuencas transfronterizas.

Esto ha permitido entender cómo se expresan este tipo de relaciones bajo la modalidad de conflicto sobre un territorio, por lo que es vital asumir la cuenca como un espacio politizado. Ha dejado de ser un espacio natural para convertirse en un espacio transformado por el ser humano; ahí convergen relaciones sociales y flujos comerciales; el río es la línea que divide estas relaciones y, a la vez, el cuerpo de agua es usado por sujetos con poder para dictar hasta dónde un Estado puede dominar. Tal situación convierte esta cuenca en un espacio producido por las relaciones de poder cambiantes, donde existen

${ }^{4}$ El thalweg se define como la línea principal del canal navegable de un río. espacios sobrepuestos con dinámicas diferentes que han de modificar el conjunto.

Entonces, el ejercicio de delimitar los Estados mexicano y guatemalteco con un río facilitó en un inicio la conformación de la frontera entre ambos países sin un costo económico alto. Pero en la actualidad ese ejercicio no ha favorecido a la población de la ribera mexicana; de hecho, el gobierno mexicano ha realizado ahí muchas inversiones millonarias que han resultado en la construcción de obras hidráulicas fallidas. Este espacio, este río no se pueden trabajar sin autorización de la CILA o la Conagua de México o del terrateniente Hugo Molina en Guatemala. De ese modo, el resultado es una ribera mexicana fragmentada en diferentes ejidos que buscan diversos intereses y una ribera guatemalteca compactada por un solo dueño que no permite realizar trabajos que desfavorezcan a su parte de la cuenca, lo cual se explicará más adelante.

\section{GÉNESIS DE LOS CONFLICTOS: LOS TRABAJOS HIDRÁULICOS EN LA RIBERA SUCHIATENSE MEXICANA}

En 1998, las precipitaciones asociadas al huracán Mitch provocaron una severa inundación en la parte baja de la cuenca del río Suchiate, la cual causó que se desbordara e inundase la ribera mexicana. Esto ocasionó pérdidas en cultivos y viviendas, principalmente de los ejidos La Libertad, Ignacio López Rayón y Miguel Alemán, entre otros. En ese entonces, la solución propuesta por la CILA-México y Conagua fue la construcción de bordos, espigones, amurallamientos en las comunidades y desazolve, para evitar que continuaran las inundaciones. Es decir, todas las soluciones se dedicaron exclusivamente a atacar al río o a su ribera.

En el 2005, con las precipitaciones asociadas con el huracán Stan, se comenzaron a vislumbrar, siete años después, ciertas irregularidades en la región omitidas desde el Mitch. Se observaron conflictos entre habitantes ribereños de ambos países y se hizo visible que los desarrollos hidráulicos del río Suchiate no habían funcionado, además de que a los anteriores trabajos no se les había dado mantenimiento. No obstante estas complicaciones con el huracán Stan, se presentó un nuevo tema: la movilidad del río Suchiate y la pérdida del territorio mexicano. 
El Universal publicó una nota el 22 de noviembre de 2005 en la cual se denunció la pérdida de territorio mexicano a causa del huracán Stan. Se mencionó ahí que 500 hectáreas quedaron en manos de Guatemala. Sin embargo, la CILA-México negó que este fenómeno haubiera modificado la frontera común. El senador priísta J. Aguilar, en esta nota, destaca que al cambiar su curso el río Suchiate dejó del lado guatemalteco parte de los ejidos de La Libertad, Miguel Alemán, Jesús Carranza e Ignacio López Rayón, los cuales representan 500 hectáreas del país (Martín 2005); dicha mención por el priísta pudo ser tomada como parte de una campaña política rumbo a las elecciones del 2006.

Sin embargo, la población ribereña mexicana se valió de los medios de comunicación impresos para hacer notar la problemática a la que se enfrentaron y se siguen enfrentando en la actualidad en temporada de lluvias, es decir, los pobladores siguieron la línea de denuncias iniciada por el senador Aguilar. Kauffer (2012a) recopiló información de campo para mostrar cuáles habían sido las señalizaciones hechas por los habitantes, además de algunos políticos que, a juicio del autor de este trabajo, se ampararon en esto para hacer campaña proselitista en periodo de elecciones, en el 2006, a favor del PRI, y se pudo comprobar que dichas señalizaciones se convirtieron en arma de doble filo. Por un lado, se apoyaba a un partido político que favorecía a la población y, por otro, se hacía notar la situación negada por la CILAMéxico de la movilidad del río Suchiate.

Durante el 2005, después del huracán Stan, los medios de comunicación fronterizos se encargaron de mostrar el descontento de la población ribereña ante la situación de las inundaciones. El 6 de octubre de 2005 se desbordó el río Suchiate como consecuencia de dicho meteoro. El resultado de esto fue la destrucción del puente Rodolfo Robles, que unía a México y Guatemala, así como del edificio de Migración y Aduanas del lado mexicano.

Además de estas destrucciones se llegó a especular sobre la movilidad de la frontera entre México y Guatemala, situación que la CILA apaciguó el 22 de octubre de ese mismo año, cuando después de algunos recorridos efectuados en la sección mexicana se determinó que no había ningún corte de tierras que implicara pérdida o ganancia de territorio en la frontera. Según la CILA, el río se desbordó pero no se movió ni cambió su cauce principal, y declaró que
«Las aguas excedentes se conducen a través de las obras de encauzamiento y estabilización construidas por ambos países para ese fin», recordando las realizadas posteriormente al huracán Mitch en 1998 ( $L a$ Jornada 2005).

Y a pesar de la negativa de CILA sobre la movilidad fronteriza, el 25 de octubre de ese año el senador Aguilar Bodegas advirtió, en un comunicado al Senado de la República, la pérdida de territorio como consecuencia del huracán. En este mensaje resalta la necesidad de reconstruir y restablecer lo dañado por el evento: la infraestructura y la vivienda, y de otorgar apoyo al campo. Puso énfasis en la crisis en la que estaban inmersos, con lo que se sumó a los problemas históricos en la frontera sur. En este mismo documento se pueden encontrar fragmentos que señalan el desinterés del gobierno federal y estatal ante los remanentes del meteoro y cómo la sociedad sigue en el desastre.

Algo muy importante que resaltó Aguilar fue el desplazamiento de la frontera entre México y Guatemala provocado por el desbordamiento del río Suchiate. Relató que tierras mexicanas ahora se encuentran del lado guatemalteco. Este documento fue citado por Días (2005) el 26 de octubre, al señalar la investigación que se desarrolló sobre la pérdida de territorio en la frontera entre México y Guatemala. Hacia noviembre 22 del mismo año Martín (2005) citó las quejas desatadas por los habitantes de la ribera mexicana con respecto a la movilidad de la frontera. En esta nota ya se habla de un número de hectáreas calculadas como perdidas, en suma cerca de 500, pertenecientes a La Libertad, Miguel Alemán e Ignacio López Rayón (Martín 2005).

En otro momento, como consecuencia de las lluvias, CILA mencionó a finales de septiembre de 2005 el deterioro del bordo suchiatense, así como inundaciones severas. «CILA, a la vez, advirtió sobre la posibilidad de un desplazamiento de tierras en la línea divisoria internacional entre México y Guatemala» (Teorema ambiental 2005).

Por lo tanto, se tiene hasta este punto una enorme contradicción en el discurso. CILA confirmó una situación en septiembre de 2005 que días más tarde negó: la movilidad del río, y en el mismo año lo convirtió en una posibilidad. Informó que la situación puede ser objeto de reclamos por parte de Guatemala, si con estas construcciones se desvía el cauce hacia ese país, aunque se solucionen las

J. Gómora • La ribera mexicana del río Suchiate, territorio fronterizo en extinción.

Conflictos generados por la abundancia del recurso hídrico 
inundaciones en la margen mexicana. Si no se realizaba esto existiría una pérdida parcial de territorio nacional. Sin embargo, esta advertencia no se tomó en cuenta. Se solicitó, por parte de los habitantes, que se reconstruyera el bordo de protección y espigones para evitar la divagación hídrica del Suchiate (Teorema ambiental 2005).

A pesar de haber afirmado que sí se modificó la frontera, el 31 de octubre de 2005, después de un recorrido por el campo, la CILA dijo que no existe ningún corte de tierras que implique pérdida de territorio. Ello resulta contradictorio con respecto a sus primeras declaraciones (Protocolo Foreign Affairs \& Lifestyle 2005).

Durante el año 2006 se llevó a cabo la propuesta ingenieril de trabajar sobre el río Suchiate. Entre promesas e incumplimientos, la CILA presentó junto con la UNAM el proyecto de desazolve del río Suchiate, el cual sería la solución idónea para las inundaciones y los desbordamientos del río fronterizo. Los conflictos se presentaron en Guatemala el 30 de marzo de 2006, cuando un grupo vecinal cerró la entrada a Tecún Umán en San Marcos y exigió el dragado del río Suchiate por los efectos del huracán Stan. Los manifestantes fueron desalojados esa misma noche con gases lacrimógenos (Castillo 2006).

La contraparte mexicana, el 31 de marzo de 2006, efectuó un bloqueo similar en el puente fronterizo de Ciudad Hidalgo. De Jesús (2006) informó que cerca de sesenta dirigentes comunales exigieron, al igual que los guatemaltecos, el dragado y la pronta acción del gobierno sobre el río Suchiate. Uno de los representantes, Abel Martínez, enfatizó que no deseaban la construcción de un muro, propuesto por el gobierno, sino el dragado del río.

Siete días antes, del 28 al 3 de abril de 2006, se habían hecho bloqueos en carreteras y manifestaciones. Los participantes eran vecinos de los municipios mexicanos de Frontera Hidalgo y Suchiate, los cuales realizaron movilizaciones para exigir el desazolve del río, en cumplimiento de lo ofrecido por el gobierno federal. Dicha movilización se vio disuelta por la supuesta entrada de la fuerza pública.

A pesar de esto, reportes oficiales calificaron de infundado este entorpecimiento fronterizo pues ya se tenía pactado con la Conagua la construcción de un bordo de cerca de $25 \mathrm{~km}$ en las márgenes, y el inicio de los trabajos de desazolve (Villalba y Mariscal 2005). Por lo que entonces apareció un nuevo ac- tor en la escena: el Fondo de Desastres Naturales (FONDEN), el cual echó a andar el amurallamiento de Ciudad Hidalgo (Mandujano 2006).

El subsecretario de Protección Civil de ese entonces, Leonardo Muñoz, comentó en un evento que la problemática enfrentada en la frontera «MexGuate» se deriva de la «franja de divagación». ${ }^{5}$ Esta se agrava por las subcuencas guatemaltecas, las cuales generan el arrastre de material. Con las quejas de los pobladores suchiatenses se logró no solo el amurallamiento, sino la construcción de espigones para regresar el río a su cauce.

Las autoridades mexicanas obtuvieron del FONDEN, para construcción de estas protecciones, cerca de 370 millones de pesos. Asimismo, el exgobernador Salazar Mendiguchía aportó la propuesta del desazolve de $40 \mathrm{~km}$ del río más la construcción de un bordo, para el cual se tenían destinados 180 millones de pesos de un total de 400 que invirtió el gobierno mexicano.

El 8 de mayo de 2006, García (2006) reportó que los trabajos para los cuales habían sido autorizados por parte de la federación 180 de los 400 millones de pesos del presupuesto, para el desazolve el río Suchiate, pedido por el gobierno del estado, no se habían realizado. Se esperaban cerca de 40 máquinas en los 12 frentes pero no ocurrió tal situación. En su momento se culpó a un retraso en el proceso administrativo, acuerdos con el gobierno de Guatemala, entre otras gestiones. Sin embargo la solución no se presentó.

\section{EL PRESENTE CONFLICTIVO DE LAS LO- CALIDADES MEXICANAS SUCHIATENSES A SIETE AÑOS DE PROMESAS Y TRABAJOS HIDRÁULICOS}

Después del paso del huracán Stan, en 2005, los habitantes de la parte baja de la cuenca del río Suchiate siguen en «pie de lucha» para obtener soluciones por parte del Ejecutivo en la protección de los ejidos y las tierras de cultivo que los habitantes poseen. En un trabajo de campo realizado en los tres ejidos más grandes de la ribera se logró tener contacto con los representantes de las localidades, para conocer su

\footnotetext{
${ }^{5}$ Esta franja de divagación es resultado del proyecto de rectificación del río Suchiate. Se refiere a la distancia, desde el cauce principal, a la cual el río tiende a moverse en su ribera.
} 
versión sobre la situación en la que se encuentran actualmente. De esto se presentan fragmentos que indican las que han sido acciones de negociación cuyas respuestas, se anticipa, no han sido positivas ni a nivel local ni a nivel federal.

\section{EJIDO IGNACIO LÓPEZ RAYÓN}

La ribera del ejido López Rayón forma parte de la gran ribera suchiatense desgastada, erosionada y con obras hidráulicas realizadas sin reparación. Esta situación no es para menos si se toman en cuenta los años que han estado en la lucha por el retorno o indemnización de sus tierras.

Le hemos pedido a la licenciada Laura Gurza (representante del FONDEN) que nos ayude a resolver este problema. Han venido, toman fotos, entrevistas y se van. Somos cerca de cinco mil habitantes, a veces pienso que porque somos muy pocos, no nos toman en cuenta, pero si nos inundamos nosotros, se inunda La Libertad y Jesús Carranza y llega esto hasta Miguel Alemán [un ejido y una propiedad privada que se encuentran algunos metros adelante así como un segundo ejido cuenca abajo] (Entrevista colectiva en ejido Ignacio López Rayón enero de 2012).
La figura 4 es una foto dentro del caudal del río Suchiate. En la temporada de la visita de campo, este se encontraba bajo. En consecuencia, se podía caminar por esta zona de inundación. Como se aprecia, esta es una gran extensión de terreno casi plano que no sirve para el trabajo agrícola, ni por el tipo de suelo ni por las crecientes del río Suchiate. Lo que se alcanza a ver en la fotografía, al fondo, en Guatemala, son las denominadas «palmas africanas». Y los arbustos que se ven frente a estas son los que evitan que esa ribera guatemalteca se siga erosionando. Es demasiado el contrastante entre la ribera mexicana, erosionada, y la guatemalteca.

¿A qué se debe esto? Al principal problema que impera en la región suchiatense mexicana, la división en parcelas, es decir, que toda la ribera mexicana del Suchiate está segmentada entre diferentes localidades y tipos de tenencia de la tierra, donde los habitantes, sus intereses individuales y colectivos se encuentran enfrentados, y muchas veces no responden al de los vecinos circundantes. Y el éxito de la guatemalteca se debe a que un solo dueño, Hugo Molina, posee toda la extensión.

Sin embargo, esto no significa que la solución sea la existencia de terratenientes en la región. El éxito

Figura 4. Fotografía de la ribera suchiatense en el ejido López Rayón dentro del caudal del río.

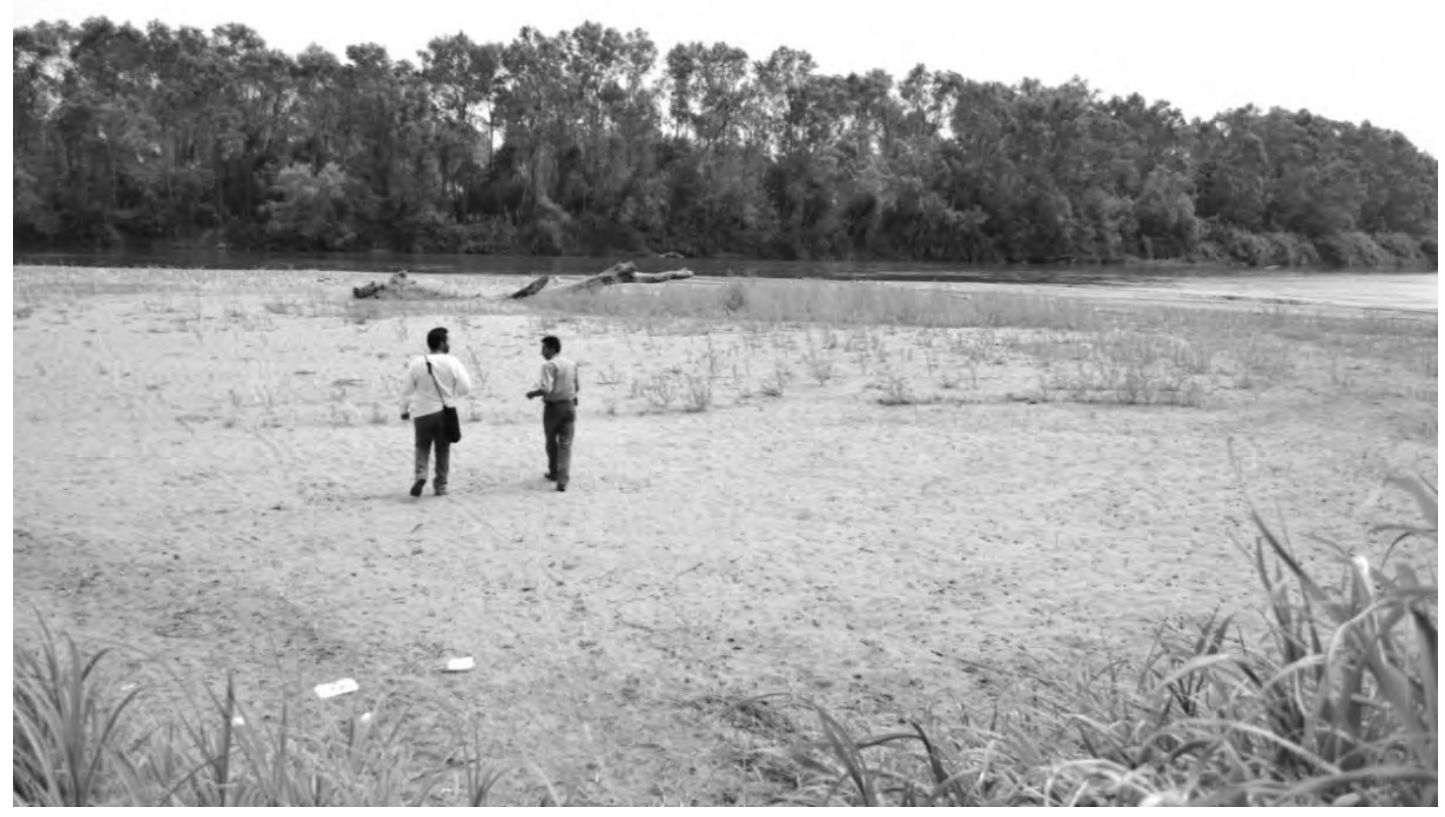

J. Gómora • La ribera mexicana del río Suchiate, territorio fronterizo en extinción.

Conflictos generados por la abundancia del recurso hídrico 
de Hugo Molina ha sido el peso económico generado por la posesión de más de 15000 ha de cultivo de frutos tropicales, principalmente el bananero, además de la falta de una ley de aguas en Guatemala. Otra cuestión por señalar es que esta división en parcelas tampoco implica que el Estado mexicano tome toda la ribera bajo su administración. Es una peculiaridad que puede servir como parámetro para comprender que es necesaria primero una sinergia entre los ribereños mexicanos para que la actividad colectiva resulte favorable para todos y no solamente para algunos.

Aunado a esto, el mencionado terrateniente ha desarrollado en la parte guatemalteca de la cuenca una notable reforestación por iniciativa propia, con diversas especies de flora que sirven para proteger la ribera de la erosión ocasionada por el río. Además, la falta de concreción de acuerdos para regular las actividades agrícolas de la porción mexicana, originada por la inestabilidad persistente en la relación entre ambas naciones, ha generado que la parte baja de la cuenca viva bajo esta oposición flagrante, donde la ribera mexicana está dividida en pequeños ejidos y la ribera guatemalteca dominada por la propiedad privada.
Otro de los conflictos recurrentes, planteados anteriormente, es la construcción de espigones y muros de contención en la ribera con el objetivo de contener y encauzar el río para evitar las inundaciones. A esto se le ha denominado obras hidráulicas por el objetivo hídrico que posee. Pero, ¿qué tan buenas son estas construcciones y qué tanto han beneficiado a la población?

Después de recorrer el espigón que se aprecia en la figura 5, el cual se encuentra completamente absorbido por la hierba que ha crecido, al igual que por la erosión ocasionada por el río, se dispuso la caminata hacia la frontera ejidal entre La Libertad y Jesús Carranza. Antes de llegar, la caminata se detuvo sobre un montículo de rocas aglomeradas sobre una pequeña porción de la ribera.

En el transcurso del recorrido y hasta su término, por la ribera suchiatense del ejido López Rayón, se puede comentar que esta ribera es la primera que debería presentar trabajos para su rescate natural e incluir un trabajo desde el aspecto ambiental. Es una ribera erosionada pero no seca. Se puede plantear este rescate en favor natural de la ribera pero ante esta solución surge el interrogante respecto del hipotético beneficio económico que trae a la población..

Figura 5. Fotografía de un espigón sin mantenimiento del ejido Ignacio López Rayón.

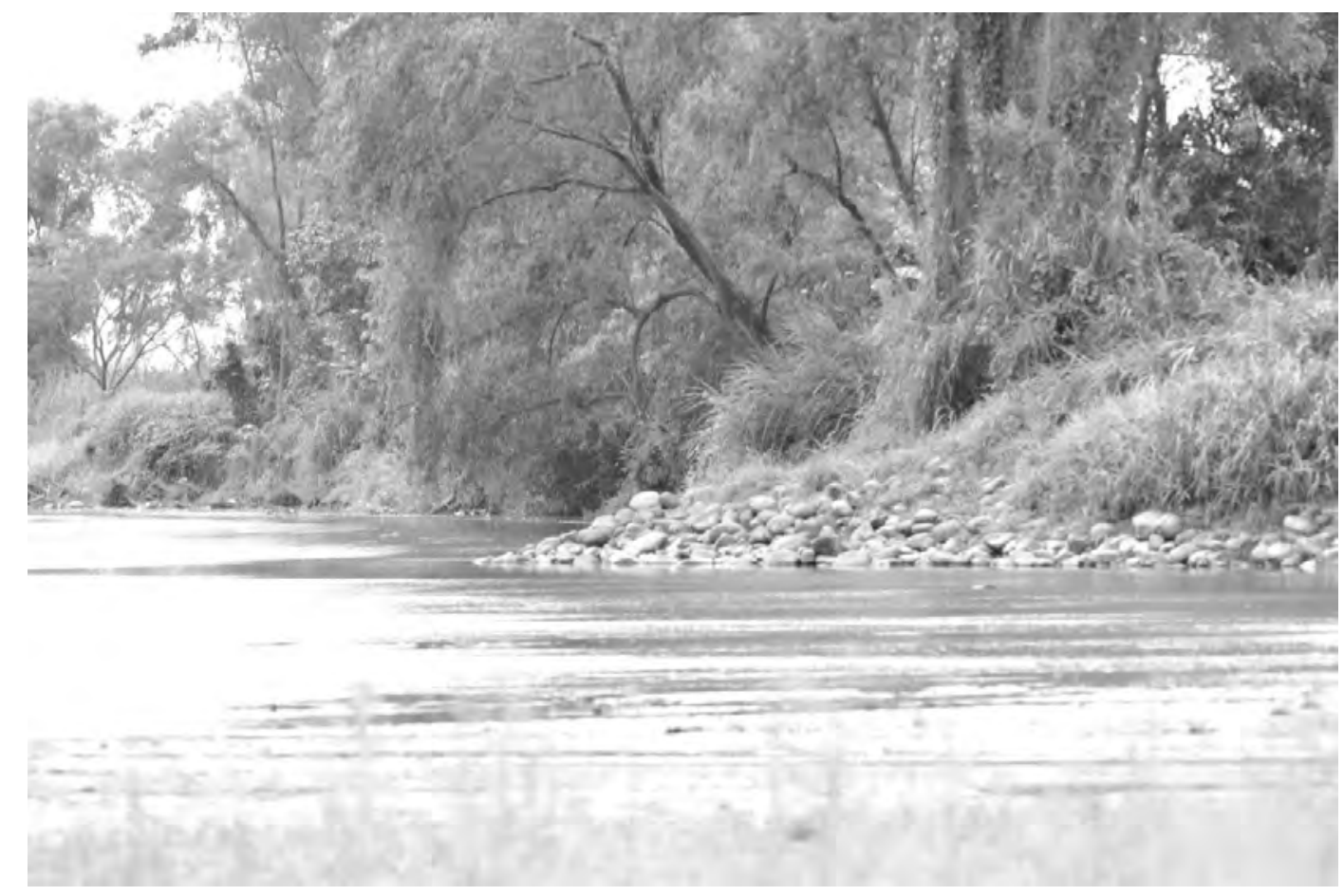




\section{EJIDO LA LIBERTAD}

El ejido de La Libertad representa en conjunto un universo complejo de estudio, debido a la explosión demográfica antes mencionada, a las soluciones ingenieriles hidráulicas, al desarrollo de propuestas sin acciones de cooperación que, en la mayoría de los casos, no han funcionado y otras no se han llevado a cabo. Resultó, entonces, relevante conversar con el comisariado, Guillermo Cruz, quien expresó un severo reclamo a las autoridades por el nulo apoyo que ha tenido dicho ejido en todos los aspectos, y subrayó la discordancia que existe entre los tres ejidos principales del Suchiate

Todo mundo tenemos deudas [...] allá sí los obligan a eso porque todos están dentro de la misma sociedad [en referencia a la población del ejido Miguel Alemán] y qué bueno, los fortalece, pero de eso a que no hayan perdido tierra, eso es una vil mentira, es ilógico. Nosotros quisimos organizarnos [...] por el peligro latente que representa, peor ahorita que la temporada de lluvias que ahora viene de manera anormal. Desgraciadamente el comisariado es nuevo, la salida del anterior, que era el que andaba con nosotros, ya a veces viene uno y no le echa ganas. Otros, como dicen ellos, ya no nos interesa. Nosotros seguimos unidos, Ignacio López Rayón. Andamos fuerte, que incluso hemos llegado hasta con la licenciada Gurza [...] también con el licenciado Cevallos del gobierno del estado [de Chiapas], él nos concertó una cita con el ingeniero Saavedra de Conagua [...] porque nosotros seguimos peleando el problema del río. Que no le hacen trabajos al río. Tenemos el miedo [...] que si una semana nos cae lluvia, día y noche, Libertad, Rayón, La Maroma (propiedad privada) y ahí se van los compañeros de Alemán, van a ver lo que es amar a Dios en tierra ajena. Para nosotros tenemos alrededor de 500, 600 hectáreas con probabilidades de desaparecer, y aquí la población bastante difícil el problema [...] toda la entrada de Libertad, es más, no pasa el vehículo [...] está tan peligroso (Entrevista colectiva junto con el ingeniero Guillermo Cruz Ávila, presidente del comisariado del ejido La Libertad, enero de 2012).

Cabe hacer mención que La Libertad es el segundo ejido que padeció los estragos de las inundaciones del huracán Stan, por lo que el FONDEN se encargó de asignar un monto de 160 millones de pesos para la restauración de su ribera, pero el recurso no llegó. Como se pudo apreciar en este fragmento de la entrevista con el ingeniero Cruz, existe una verda- dera asinergia en la parte baja. No se cuenta con la participación de todos los ejidos, a pesar de padecer el mismo problema. Sin embargo, la otra situación que debilita el engranaje de la cooperación es la lejanía de los centros de poder para la realización de los acuerdos. Todo genera un costo, ya sea el transporte de los representantes o la construcción de las obras hidráulicas.

El recorrido continuó hacia la ribera del ejido $\mathrm{La}$ Libertad. En una visita anterior, en el 2011, el acompañamiento fue limitado a una o dos personas. Sin embargo, en la suma de esfuerzos por ayudar a esta investigación la camioneta de trabajo se completó con cerca de 10 habitantes del ejido. Ellos justificaban su asistencia por la pérdida que habían padecido. Cabe mencionar que el lugar se ha vuelto peligroso para los habitantes, así como para las personas que no son de ahí.

Al llegar al río lo primero que se observó fue un espigón en ruinas, como se aprecia en la figura 6. Esta situación se repetía en los otros espigones. Al platicar con los acompañantes se percibió su preocupación y la incertidumbre que permea en todos por no saber qué seguirá y si algún día se hará efectiva esta entrada de recursos para rescatar la ribera mexicana.

La Conagua les pidió que aprendieran a vivir con el río, pero ellos desean impedir que el río haga lo que quiera con ellos. La postura que mantienen los habitantes es: «Nosotros no queremos recuperar tierras, es difícil, pero no queremos que se las siga llevando» (Entrevista con el ingeniero Guillermo Cruz Ávila, presidente del comisariado del ejido La Libertad, enero de 2012).

Durante el recorrido se llegó a otra porción completamente erosionada, pues se compone principalmente de limos depositados en la ribera por la carga del río Suchiate (figura 7). Todo este material de azolve es el que se pretende erradicar en el cauce del río, pero, ¿realmente es una solución viable?

Cuando el río comienza a subir en la temporada de lluvias (mayo-septiembre) esta minúscula llanura se inunda, viene más material de arrastre (figura 7) y surge una pregunta: ¿Dónde queda el thalweg? Ni los pobladores saben dónde está. Ellos ven el río como el límite, y solamente algunos saben que la delimitación está en el canal más profundo del Suchiate, de lo cual se colige que el tema de la frontera sale sobrando y lo que realmente se necesita plantear es la permanencia de los ejidos dentro del territorio mexicano. 
Figura 6. Espigón en ruinas del ejido La Libertad.



Figura 7. Fotografía del caudal del río Suchiate en la temporada seca del año.

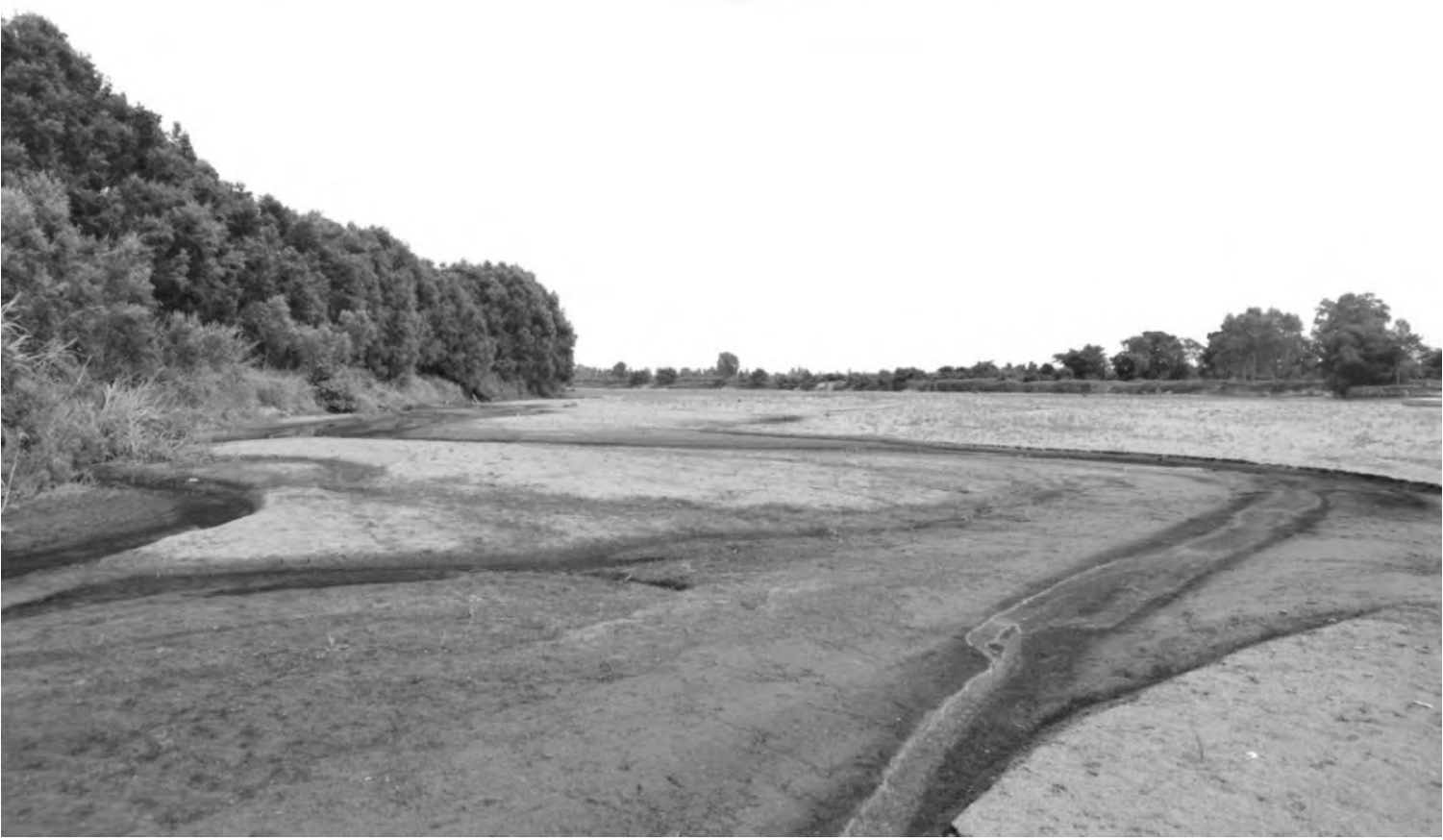


Justamente esta llanura (figura 7), cerca de uno de los espigones que mencionaba el ingeniero Cruz Ávila, se encuentra también en ruinas, quedan algunas rocas que pueden aguantar la carga de un río en enero, pero no del gasto que llega a tener el Suchiate en los meses de mayo o junio. Sobre el espigón ya está creciendo vegetación que no sirve para la población, ni beneficia al propio espigón.

La preocupación del ejido La Libertad se centra en el ejido López Rayón, al cual señalaron como endeble para soportar otro temporal con tal fuerza como el ocasionado por el huracán Stan y la creciente del mismo Suchiate. Este ejido, junto con Rayón, las propiedades privadas de La Maroma, y Jesús Carranza han buscado generar sinergia para llegar a las autoridades, pero no han tenido éxito.

\section{EJIDO MIGUEL ALEMÁN}

El ejido Miguel Alemán es el último correspondiente al municipio de Suchiate en México. Tiene menos de la cuarta parte de población que el de López Rayón. Sus habitantes están organizados para la preservación y el cuidado de su entorno. Pero, ¿qué tiene de especial este ejido, si todo es «normal» ahí, en opinión de los habitantes? Precisamente, por parte de sus representantes existe una desvinculación con la dinámica de los problemas que se encuentran con los ejidos vecinos del norte.

Miguel Alemán es un ejido cercano a la desembocadura del río Suchiate y se trata de la última localidad ubicada cuenca abajo en la ribera mexicana. No posee una ribera curvada, por lo que la fuerza del río, al desaguar, llega directamente a la desembocadura y no al ejido. En consecuencia, el desbordamiento del río no es, a simple vista, un problema grave.

En entrevista con la representante de seguridad de este ejido, Sandra Vilchis, se obtuvo la siguiente información:

Pues no estuvo tan fuerte como en López Rayón o La Libertad. Acá sí llovió fuerte, nos inundamos hasta la mitad de la pantorrilla pero no pasó de eso. ¡Ora verá! Cuando se vino la tormenta, sí nos inundamos, es más, algunos medios de comunicación espantaron a nuestros familiares que estaban en otros lugares porque habían dicho que nuestro ejido había desaparecido. Pero al comunicarnos, pudimos dar la noticia de que eso no había sido verdad... [...] vinieron los militares, vinieron y nos sacaron a todos, nos evacuaron. Cuando me tocó a mí, uno de los soldados me preguntó si en verdad por aquí había pasado el huracán, que por qué no veía nada de lo que en otros ejidos había visto.

La entrevista con la señora Vilchis fue bastante ilustrativa. El ejido Miguel Alemán posee un enigmático sistema de perfectibilidad social funcional, es decir, sus habitantes responden a dinámicas y reglas establecidas por la misma localidad para que no exista un descontrol en las actividades cotidianas y la seguridad. Ellos están organizados en una cooperativa, la cual se encarga de la vigilancia. Se dice que este ejido es uno de los pasos fuertes del narcotráfico, de lo cual no se pudo tocar el tema, a reserva del personal de Protección Civil que acompañó este recorrido.

Hablar del ejido Miguel Alemán es hablar de la conformación de una unidad espacial utópica. Su restructuración y restauración en los últimos dos años ha sido gigantesca en comparación con $\mathrm{La}$ Libertad y López Rayón. Este señalamiento se basa en la conformación de la ruta del plátano (González 2011), del cual este ejido es destino final. Por otro lado, cabe destacar la limpieza en este ejido (figura 8) y por último los trabajos de pavimentación hidráulica en sus calles.

Este ejido rompe con el espacio problemático de la ribera, por el hermetismo visible que posee la población. Se habla de una cooperación entre los habitantes, de narcotráfico en la región, del sustento del ejido gracias a su invernadero de chile habanero. Pero lo cierto es que logró focalizar su desarrollo en otro aspecto que va desde el turismo hasta la producción de otro cultivo en la región bananera.

Se puede concluir, entonces, que esta dinámica de desagregación problemática con otros ejidos, en torno al río Suchiate, es producto de la focalización de desarrollo mencionada en el párrafo anterior, $y$, aunado a esto, la inversión del tiempo en otros aspectos, fuera de la participación en la movilización por la pérdida de ribera del río Suchiate.

\section{CONCLUSIÓN}

El agua y su escasez, conflicto recurrente en cuencas y cuencas transfronterizas, no es la problemática central, en especial en la del río Suchiate. Este trabajo se enfocó hacia la muestra y el análisis de los conflictos que se han presentado, así como en las 
Figura 8. Explanada principal del centro del ejido Miguel Alemán.

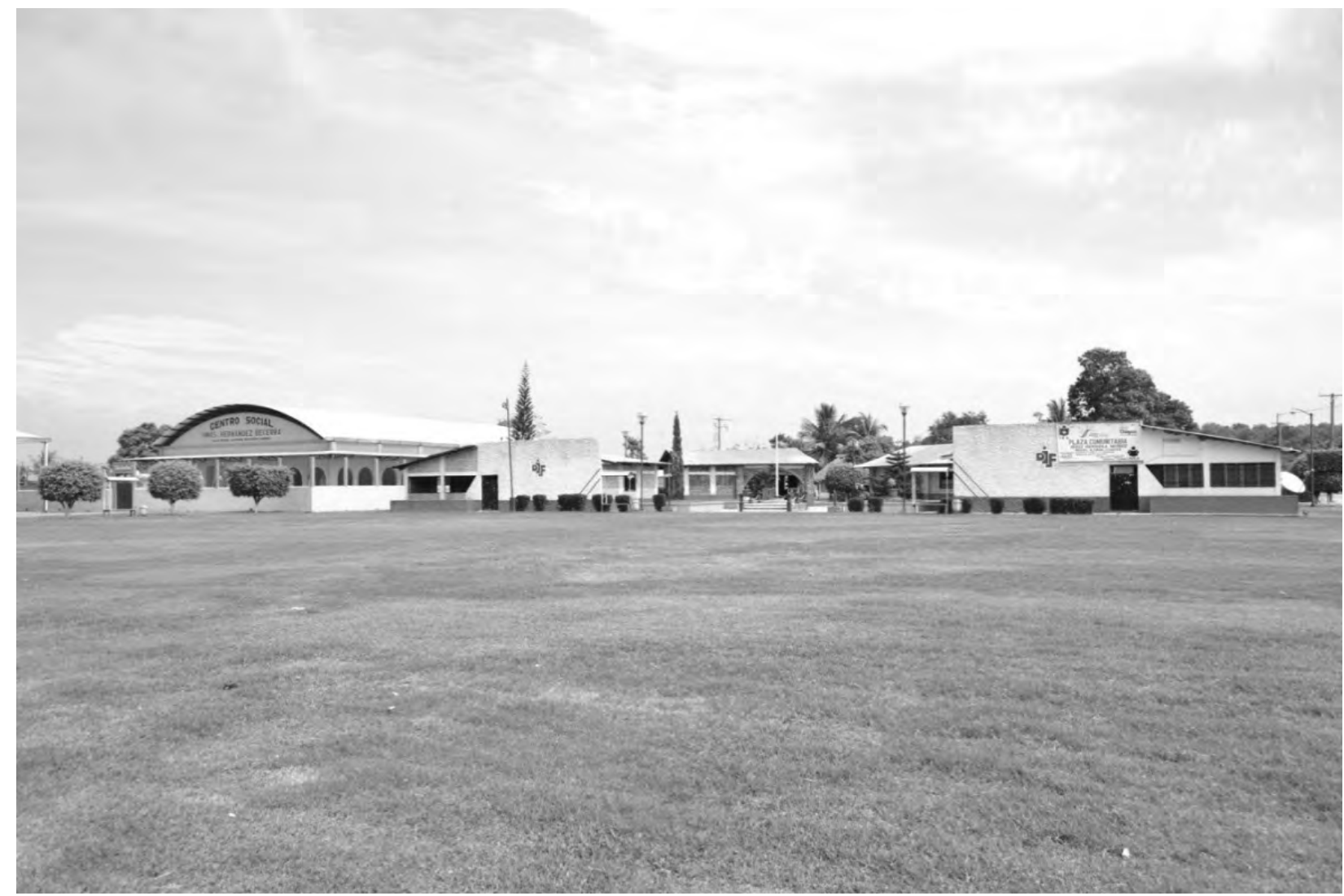

respuestas de corte hidráulico ingenieril que se han utilizado para disminuir las consecuencias de los desastres que se pueden originar ahí, así como las dinámicas ejidales que han potenciado el conflicto.

Los hallazgos durante el trabajo de campo y la consulta de fuentes informativas, con respecto a la evasión del tema de la movilidad del río Suchiate, entre México y Guatemala, arrojaron que, en primer lugar, las elites de gobierno y de organizaciones de derecha de ambos países evaden y trastocan el tema de la movilidad. Existe un grupo de actores académicos, sociales y políticos en Guatemala que interviene activamente con opiniones como las de José Luis Cabrera (De la Torre y Cabrera 2008), citado líneas arriba, quien declaró en una conferencia dictada en la Universidad Francisco Marroquín, de Guatemala, que la única solución que se le puede dar al tema del Suchiate es que México le regrese a Guatemala el Soconusco.

Es decir, el tema de la división política entre ambos países realizada en 1882, así como el del despojo de tierras del Petén, que él señala en su conferencia, siguen en el imaginario. Por lo tanto, no se ha podido avanzar en materia de cooperación, porque la postura es que el gobierno mexicano reconozca esa etapa de la historia que está oculta, incluso en los libros de historia de México.

Del lado mexicano existe una fuerte tendencia, principalmente de la CILA-México, a evitar tocar el tema, incluso a negar que existan disputas por la ribera del Suchiate, para que no se malentiendan las acciones que pueda tomar, debido a que la región es una frontera internacional. Entonces, lo que se tiene es una relación en la cual quienes toman las decisiones no se ponen de acuerdo porque tanto el contexto político fronterizo como el contexto histórico les impide entablar un diálogo que facilite la sinergia entre ambas naciones. Lo que da como resultado que la frontera no exista, que los pobladores sean parte del paisaje fronterizo pero que todo lo que pueda repercutirles no sea tema de cooperación internacional, mucho menos de una mesa de diálogo binacional.

El potencial conflicto binacional en torno a las divagaciones del río, por consecuencia de los eventos meteorológicos es, por lo tanto, un tema que se trata desde una postura unilateral. Las decisiones se 
toman desde cada ribera, mexicana o guatemalteca, hacia el centro de cada nación, sin considerar al vecino, al de enfrente. En lugar de ver el río como parte del territorio, lo ven como algo intocable. Entonces, la población, en 1998, con el Mitch, como se pudo apreciar, aceptó la construcción de obras de corte hidráulico para no volver a padecer con el tema del Suchiate, pero en el 2005, con el Stan, las consecuencias se acrecentaron.

De este modo, cada ribera, en época de lluvias, desde el aspecto político, evita tomar en cuenta a la población ribereña, así como a la ribera vecina, y las consecuencias son que en la ribera de México, al estar fragmentada, se adopten acciones multidireccionadas para evitar las inundaciones, la erosión y la pérdida de territorio, entre otros aspectos. El ingeniero Ávila de La Libertad claramente lo dijo: «Siete días y siete noches de lluvia, e Ignacio López Rayón y La Libertad desaparecen».

En suma, se tiene un escenario en completa desfragmentación social. Aunado a esto, las causas del desplazamiento del río, como el desarrollo de cultivos que no son propios de la región, así como la construcción de viviendas cercanas a la ribera y que la parte alta de la cuenca tampoco tiene un sistema de protección, conducen a que al atacar un problema se desatiendan otros.

La situación aquí es que el gobierno mexicano no está dispuesto a pagar a sus homólogos en Guatemala los servicios ambientales en la parte alta de la cuenca del Suchiate. La postura de Guatemala es la de «cuencas soberanas» y que se les tiene que retribuir con un incentivo económico para que se preocupen de que la cuenca en la parte alta no se erosione ni se deforeste, $\mathrm{y}$ de ese modo evitar que el material de acarreo no se deposite en la parte baja y genere ese tapón que impide que el río llegue hasta su desembocadura.

Esto desde la parte alta. Desde la parte baja, ambas riberas tienen actores diferentes. Como se destacó con anterioridad, la ribera mexicana se erosiona porque no se realizan los trabajos necesarios ni se da capacitación a los habitantes para evitar el desgaste, ni se les proveen los insumos necesarios para que puedan rescatar parte la ribera. Hugo Molina supo capitalizar su ribera. Se movió el río, las 500 ha están en Guatemala y este terrateniente supo en qué momento reforestar para que el río no vuelva a moverse de su cauce original. Entonces, los afectados por esto son los del lado mexicano, porque no han logrado que los ejidatarios trabajen en la protección de sus tierras.

Queda, al final, un interrogante por responder: ¿Cuál sería una posible solución para evitar los conflictos ocasionados por el río Suchiate: el dragado del río, o que el gobierno mexicano retome el control y la administración de la ribera, o bien que se replantee la cuestión de la frontera, o tener un terrateniente, como en Guatemala, o que México pague los servicios ambientales?

Todas las variables exigen un grado importante de cooperación internacional. En primer lugar se habla de una frontera. Lo que la CILA-México ha hecho es vender muy bien la idea de que el dragado es la solución. Sin embargo, es una respuesta costosa (al igual que los bordes, muros y espigones) y que a la larga se puede volver a requerir. La cuestión sería: ¿qué pasa si Guatemala no quiere? La ribera de Guatemala no es nacional, es privada, y su dueño se ha opuesto a todas las acciones para el dragado del río.

La variable del terrateniente no es ni viable, ni necesaria. Lo que se necesita en la ribera es diálogo y capacitación para entender qué ocurre a, así como la continuación de los programas sociales para que los ejidatarios ribereños conozcan los pros y contras de una ribera descuidada, pues ya lo han vivido.

A nivel diplomático, el tema es complejo porque algún roce que se llegue a generar puede elevar un conflicto a disputa violenta. Entonces, lo que se propone es que se entablen negociaciones entre ambas naciones para que México pague, así como lo hace con Estados Unidos, los servicios ambientales. Situación que se ve como imposible debido a la rispidez de la relación en términos de este tema y a que se sigue percibiendo a México como país hegemónico en la región.

\section{FUENTES DE CONSULTA}

Álvarez, Salvador, 2011, «Patrimonio territorial y fronteras: la visión del Estado mexicano en el siglo XIX» en C. Herrejón (coord.), La formación geográfica de México, I. El Patrimonio Histórico y Cultural de México (1810-2010), Conaculta, México, pp. 70-125.

Ávila García, Patricia, 2009, «Cambio global y recursos hídricos en México: hidropolítica y conflictos contemporáneos por el agua», Instituto

J. Gómora • La ribera mexicana del río Suchiate, territorio fronterizo en extinción.

Conflictos generados por la abundancia del recurso hídrico 
Nacional de Ecología y Cambio Climático, México, en www.ine.gob.mx/descargas/cuencas/cambio_global_y_rec_hdricos_mex.pdf [consulta: 30 de octubre 2012].

Camp, Roderic Ai, 1975, «La Cuestión chiapaneca: Revisión de una polémica territorial», Revista de Historia Mexicana, v. 24, n. 4, pp. 579-606, El Colegio de México, Centro de Estudios Históricos, en codex.colmex. mx:8991/exlibris/aleph/a18_1/apache_media/ ASR949TR88J9HDD2MBCDDE3M1G5VB. pdf [consulta: 30 de octubre 2012].

Castillo, Jorge, 2006, «Paso Cerrado en Tecún Umán: Vecinos demandan dragado de río Suchiate», Prensa Libre, en www.prensalibre. com/p1/2006/marzo/30/138176.html [consulta: 19 de octubre 2012].

Días Flores, Mary José, 2005, «El Senado pide al presidente Fox una amplia investigación sobre la pérdida de territorio en la frontera entre México y Guatemala», Por las Cañadas, en www.columnasur.org [consulta: 10 de octubre de 2012].

García, Ramón, 2006, «No llegaron las 40 máquinas para empezar los trabajos de desazolve del río Suchiate», Cuarto Poder, en www.cuartopoder.mx [consulta: 10 de noviembre de 2012].

Gérardot, Maie, Philippe Lemarchand (dirs.), et al., 2011, Géographie des conflits, Editorial Atlande, Colección Clefs Concours, Géographie Thématique, Francia.

González Chay, Rosario, 2011, «Cruceristas recorren la "Ruta del Plátano"», Diario del Sur, en www. oem.com.mx/diariodelsur/notas/n1944948.htm [consulta: 17 de octubre de 2012].

González Lezama, Raúl A., s. f., «Incorporación de Chiapas al pacto federal, 14 de septiembre de 1824», Archivo electrónico del Instituto Nacional de Estudios históricos de las Revoluciones de México (INEHRM), México, en www.inehrm.gob.mx/Portal/PtMain. php?pagina $=$ exp-chiapas-al-territorio-federal-articulo [consulta: 27 de mayo de 2013].

Instituto Nacional de Estadística de Guatemala (INE), 2008, Estimaciones de la Población total por municipio. Periodo 2008-2020, en $\mathrm{http} / / / \mathrm{www}$.ine.gob.gt/np/poblacion/index.htm [consulta: 13 de junio de 2012].
— 2005 , Prontuario de información geográfica municipal de los Estados Unidos Mexicanos, Suchiate, Chiapas, INEGI, en www.inegi.org. $\mathrm{mx} /$ sistemas/mexicocifras/ datos-geograficos/ 07/07087.pdf [consulta: 30 de enero 13].

—_ s.f., «Referencias geográficas y extensión territorial de México», INEGI, en www.inegi.org. $\mathrm{mx} /$ inegi/spc/doc/internet/1GeografiaDeMexico/man refgeog extterr vs enero 302088 . pdf [consulta: 20 de octubre de 2012].

Kauffer Michel, Edith F., 2010a, «La cuenca del río Suchiate: entre inundaciones y movilidad de la frontera México-Guatemala», en Las cuencas hidrográficas de México. Diagnóstico y priorización, H. Cotler (coord.), Exima/Instituto Nacional de Ecología y Cambio Climático, México, pp. 198-200, en www.ine.gob.mx/publicaciones/libros/639/rsuchiate.pdf [consulta: 20 de noviembre de 2012].

__ 2010b, «Hidropolítica del Candelaria: del análisis de la Cuenca al estudio de las interacciones el rio y la sociedad ribereña», Relaciones. Estudios de Historia y Sociedad, v. 31, n. 124, pp. 187-226.

Kauffer Michel, Edith F., 2012a, «Conflictos y cooperación en cuencas transfronterizas del sur de México y de Centro América: dinámicas históricas y realidades contemporáneas», proyecto presentado en el taller temático México-Francia Cuencas transfronterizas en la encrucijada de la cooperación y los conflictos: miradas cruzadas en el tiempo y el espacio (México, Francia $y$ Centroamérica), del 16 a 18 de enero, París. , 2012b, «Agua y desastres en las cuencas transfronterizas del sur de México: Políticas públicas vs. Respuestas locales», ponencia presentada en el evento Intercambio Fronterizo de Reducción de Riesgos de Desastres entre Departamentos Guatemaltecos y el Estado de Chiapas, Programa de las Naciones Unidas para el Desarrollo PNUD, 2 a 4 de mayo, Tapachula.

_, $2010 c$, «Migraciones y agua en la frontera entre México, Guatemala y Belice: aproximaciones en torno a una relación multiforme», Liminar, v. 8, n 2, CESMECA-UNICACH, pp. 29-45, en redalyc.uaemex.mx/redalyc/ pdf/745/74516321003.pdf [consulta: 4 de junio 2012]. 
La Jornada, 1996, «Zedillo: México y Guatemala buscan construir una "frontera ejemplar"», La Jornada, en www.jornada.unam. mx/1996/09/10/zedilloguate.txt. html [consulta: 8 de agosto 2012].

La Jornada, 2005, «Niegan que el río Suchiate haya cambiado de curso», La Jornada, en www. jornada.unam.mx/2005/10/22/index.php?section $=$ politica $\&$ article $=016 \mathrm{n} 3 \mathrm{pol}$ [consulta: $6 \mathrm{de}$ agosto 2012].

Mandujano, Isaín, 2006, «Levantarán muro en la frontera sur... para evitar inundaciones», Proceso, disponible en www.proceso.com.mx/ notici.html?sec=1\&nta=39311 [consulta: 9 de agosto 2012].

Martín Pérez, Fredy, 2005, «México pierde territorio a causa de "Stan", denuncian», El Universal, en www.eluniversal.com.mx [consulta: 5 de septiembre de 2012].

Olvera, David, Edith Kauffer, Birgit Schmook y Laura Huicochea, 2011, «Factores de conflicto en la cooperación por el agua en cuencas compartidas: caso Río Hondo (México-GuatemalaBelice)», Estudios fronterizos, Nueva Época, v. 12 , n. 24 , pp. 103-134, en www.uabc.mx/iis/ ref/REFvol12num24/EFVOL12NUM24-4.pdf [consulta: 2 de febrero de 2012].

Pérez de los Reyes, Marco A., 1988, «El Soconusco y su Mexicanidad (breves consideraciones)», Anuario del departamento de Derecho de la Universidad Iberoamericana, n. 12, Instituto de Investigaciones Jurídicas, UNAM, México, pp. 473-501, en www.juridicas.unam.mx/publica/librev/rev/jurid/cont/12/pr/pr20.pdf [consulta: 25 de mayo de 2013].

Protocolo Foreign affairs \& lifestyle, 2005, «Huracán Stan no modificó frontera con Guatemala», en www.protocolo.com.mx [consulta: 8 de mayo de 2012].

Santacruz de León, Germán, 2010, «¿Crisis del agua? Enfoques de gestión y estudio de caso», en L. Torre y C. Hernández Suárez (coords.), Gestión, políticas y culturas del agua, Red de Colegios y Centros de Investigación (RECCI)/ Colegio de San Luis, San Luis Potosí, pp. 17-29, en www.colsan.edu.mx/investigacion/aguaysociedad/gestion_agua/archivos/ Gestionpoliticasagua31ju12010.pdf [consulta: 14 de noviembre de 2012].
Santacruz de León, Germán, 2011, «Problemática ambiental y conflictos sociales en torno al uso del agua en la cuenca del río Suchiate», en E. Kauffer (coord.) Entre manantiales y ríos desatados: Paradojas de las hidropoliticas fronterizas (México-Guatemala), CIESAS-COLMICH, México (Publicaciones de La Casa Chata), pp. 35-58.

Sepúlveda, César, 1958, «Historia y problemas de los límites de México», Revista Histórica Mexicana, v. 8, n. 230, El Colegio de México, Centro de Estudios Históricos, México, D.F., pp. 145-174, en codex.colmex. mx:8991/exlibris/aleph/ a18_1/apache media/ NAPGUNDVF557QSEXE9QFBM5M3XBT. pdf [consulta: 18 de mayo 2013].

Teorema Ambiental, 2005, «La CILA advirtió sobre posible cambio del cauce del Suchiate», disponible en www.teorema.com.mx [consulta: 4 de septiembre de 2012].

Torre, Armando de la y José Luis Cabrera, 2008, «Las fronteras disputadas entre México y Guatemala», conferencia impartida en la Universidad Francisco Marroquín, disponible en newmedia.ufm.edu/gsm/index.php/Las disputadas_fronteras [consulta: 16 de marzo 2012].

Vázquez Olivera, Mario, 2009, El imperio mexicano y el Reino de Guatemala. Proyecto político y campaña militar 1821-1823, Fondo de Cultura Económica/CIALC/PROIMMSE-IIA-UNAM, México.

Villalba, Rodolfo y Ángeles Mariscal, 2005, «Vecinos de Suchiate y Frontera levantan bloqueos que comenzaron hace 7 días», $L a$ Jornada, disponible en www.lajornada.unam. mx/2006/04/03/038nlest.php [consulta: 3 de octubre 2012].

Wolf, T. Aaron, Annika Kramer, Alexander Carius, Geoffrey D. Dabelko, 2005, «Gestionando conflictos por el agua y cooperación» en $\mathrm{M}$. Renner, H. French y E. Assadourian (dirs.), $L a$ Situación del Mundo 2005: Redefiniendo la seguridad mundial, Informe anual del Worldwatch Institute sobre el progreso hacia una sociedad sostenible, Icaria/Centro de Investigación para la Paz, Barcelona. pp. 155-184.

J. Gómora • La ribera mexicana del río Suchiate, territorio fronterizo en extinción.

Conflictos generados por la abundancia del recurso hídrico 


\section{ENTREVISTAS}

Ejido Ignacio López Rayón

Entrevista con el Ingeniero Marcelino Valenzuela, presidente del comisariado del ejido Ignacio López Rayón, enero de 2012.

Ejido La Libertad

Entrevista con el Ingeniero Guillermo Cruz, presidente del comisariado del ejido La Libertad, enero de 2012.
Entrevista colectiva con habitantes del ejido, con participación del ingeniero Guillermo Cruz, enero de 2012.

Ejido Miguel Alemán

Entrevista con la señora Sandra Vilchis, consejera de seguridad del ejido Miguel Alemán, enero de 2012. 